\title{
The Effect in vitro of the Steroidal Component of Oral Contraceptives on Platelet Aggregation
}

Many reports ${ }^{1-4}$ describe a statistically significant increase of thromboembolic disease caused by the intake of oral contraceptives. The exact mechanism of the effect has not been clearly determinated. These studies have been made specially in vivo after several weeks of drug ingestion. An increase in platelet aggregation using the Chandler's tube technique ${ }^{5}$ and the sensitivity to adenosine diphosphate determined by the electrophoretic technique, have been described ${ }^{6}$.

A recent paper reported an increase of platelet $A D P$ induced aggregation in vitro ${ }^{7}$. Nevertheless, the final concentration of the drugs studied was several times higher than the level we expected to find in blood in vivo after oral ingestion.

The object of this study is to establish the effect of these components in concentrations close to the physiological state on platelet aggregation in vitro.

Material and methods. Blood was collected from fasting healthy people, 10 days after the suppression of any medication. Platelet-rich plasma (PRP) and platelet-poor plasma were obtained by differential centrifugation in an International B 20. The PRP was adjusted at 300,000

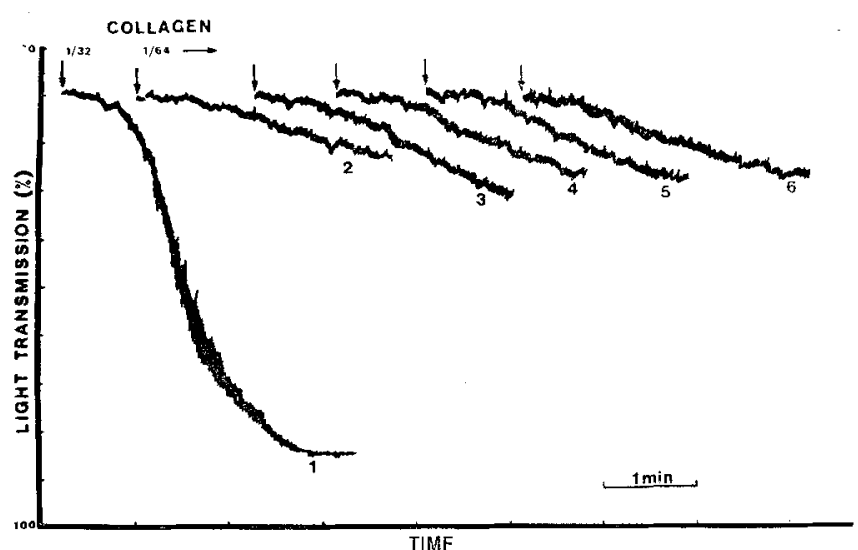

TIME

Fig. 1. PRP 300,000 platelet $/ \mathrm{c} \mu / \mathrm{mm}$ final concentration $(\mathrm{FC})$ was incubated with distilled water (curves 1 and 2), propilenglycol 1/1000 $\mathrm{FC}$ (curve 3), norethinodrel or norethindrone $1.25 \times 10^{-6} \mathrm{FC}$ (curve 4), mestranol $4 \times 10^{-7} \mathrm{FC}$ (curve 5), norethinodrel $1.25 \times 10^{-6}$ and mestranol $4 \times 10^{-7} \mathrm{FC}$ during $10 \mathrm{~min}$ and then the indicated amount of collagen added for inducing aggregation. Curve 1 shows the ability of aggregability of the platelet. Comparison of curve 2 with the other curves shows no differences in platelet aggregation.

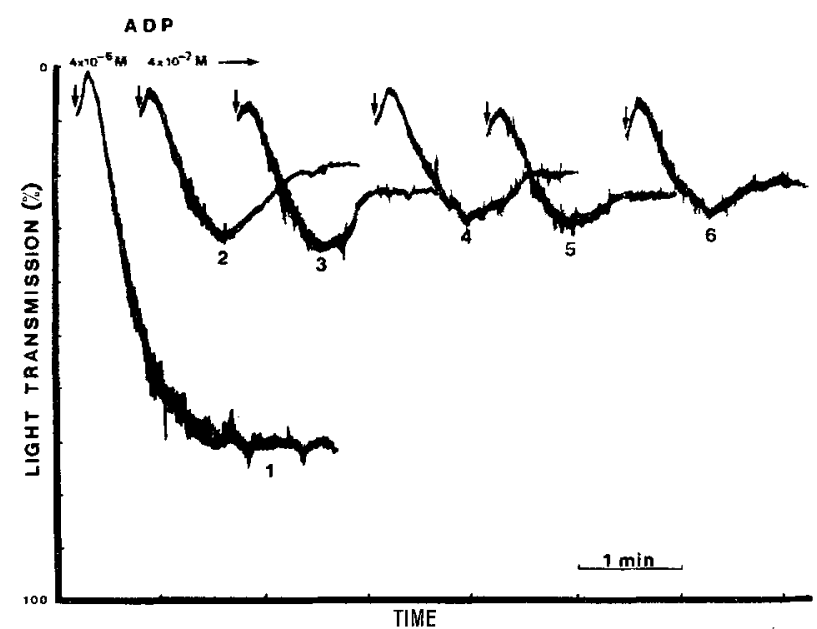

Fig. 2. The same as in Figure 1, using ADP in the concentration indicated, as aggregation agent. No difference in platelet aggregation could be detected. platelet $/ \mathrm{mm}^{3}$ final concentration. Platelet aggregation was followed at $37^{\circ} \mathrm{C}$ using the turbidimetric method of BORN ${ }^{8}$ with the Born M.K. II aggregometer.

The drugs to be tested were used in a final concentration of $4 \times 10^{-5} \mathrm{M}$ to $4 \times 10^{-7} \mathrm{M}$ for mestranol and $2.5 \times 10^{-4} \mathrm{M}$ to $2.5 \times 10^{-7} M$ for norethindrone and norethinodrel. The test compounds were used in an aqueous suspension. A concentrated solution was made in propylenglycol (mestranol $4 \times 10^{-2} M$ and norethinodrone and norethinodrel $5 \times 10^{-2} M$ ) and then diluted with distilled water to the working solution.

Without, or after 10 min incubation of the PRP with the compounds, adequate amount of human collagen prepared by saline extraction of Achilles' tendon, or ADP (Boehringer Mannheim, Lot No 7520277) to a final concentration of $4 \times 10^{-6} M$ and $4 \times 10^{-7} M$ was added, and the changes in light transmission were recorded. Controls were obtained by measuring the platelet aggregation caused by similar concentration of collagen and ADP in presence of distilled water or propylenglycol.

Results and discussion. The results are shown in Figures 1 and 2 . The drugs used in these experiments, alone or together, and in different concentrations, showed a lack of effect on platelet aggregation.

Because the metabolism of progestogens and estrogens is rather fast, it was not supposed that they would increase in the plasma level after daily oral ingestion of contraceptives. Their concentrations in blood should not be as high as that used by CLAYMAN, GADD and HERBERT? However, various drug concentrations were used ranging from that close to physiological level to several times more, without increase on platelet aggregation.

Moreover, as the drugs used in the present experiment are water-insoluble, a concentrated solution in propylenglycol was prepared, which was then diluted with distilled water. In this way a solution was obtained in which the propylenglycol concentrations did not affect platelet aggregation. This solution enables in vitro results to be extrapolated to in vivo situations.

This investigation leads us to suppose that the thromoembolic complication is not due to an increase of platelet aggregation, and may be related to plasma and/or to vessel wall alterations ${ }^{6-9}$.

Résumé. On étudie l'effet de l'estrogène mestranol et des progestogènes noréthindrone et noréthinodrel sur l'agrégation plaquetaire in vitro quand leur concentration est semblable à celle qu'ils sont supposés dans le sang après l'administration orale. Les résultats obtenus permettent de conclure que ces composés ne produisent aucune augmentation de l'agrégation plaquetaire.

\section{R. Altman, Silvia Taboada and A. Zielinsky}

Departamento de Docencia e Investigación,

U.A.M.I. Rivadavia-Peralta Ramos, Las Heras 2670 , Buenos Aires (Argentina), 17 May 1974.

1 W. H. W. Inman and M. P. Vessey, Br, med. J. 2, 193 (1968).

2 M. P. VESSEY and R. DolL, Br. med. J. 2, 199 (1968).

3 M. P. Vessey and R. Doll, Br. med. J. 2, 651 (1968).

${ }^{4}$ W. H. W. Inman, M. P. Vessey, B. Westerholm and A. EngeLUND, Br. med. J. 2, 203 (1970).

${ }^{5}$ L. Poller, C. H. PRIest and J. M. Thonson, Br, med. J. 4, 273 (1969).

${ }^{6}$ C. H. Bolton, G. H. Hampton and J. R. A. Mitchell, Lancet 1 , 1336 (1968).

7 S.Clayman, R.E.A. Gadd and D.Hebert, Experientia 29, 95 (1973).

${ }^{8}$ G. V. Born and M. J. Gross, J. Physiol, Lond. 168,178 (1963).

${ }^{9}$ O. Egeberg and P. A. OWren, Br. med. J. 1, 220 (1963). 